\title{
Metabolic network capacity of Escherichia coli for Krebs cycle-dependent proline hydroxylation
}

Eleni Theodosiou ${ }^{1,2}$, Oliver Frick², Bruno Bühler ${ }^{1,2^{*}}$ and Andreas Schmid ${ }^{2}$

\begin{abstract}
Background: Understanding the metabolism of the microbial host is essential for the development and optimization of whole-cell based biocatalytic processes, as it dictates production efficiency. This is especially true for redox biocatalysis where metabolically active cells are employed because of the cofactor/cosubstrate regenerative capacity endogenous in the host. Recombinant Escherichia coli was used for overproducing proline-4-hydroxylase (P4H), a dioxygenase catalyzing the hydroxylation of free L-proline into trans-4-hydroxy-L-proline with a-ketoglutarate (a-KG) as cosubstrate. In this whole-cell biocatalyst, central carbon metabolism provides the required cosubstrate $a-K G$, coupling P4H biocatalytic performance directly to carbon metabolism and metabolic activity. By applying both experimental and computational biology tools, such as metabolic engineering and ${ }^{13} \mathrm{C}$-metabolic flux analysis $\left({ }^{13} \mathrm{C}-\mathrm{MFA}\right)$, we investigated and quantitatively described the physiological, metabolic, and bioenergetic response of the whole-cell biocatalyst to the targeted bioconversion and identified possible metabolic bottlenecks for further rational pathway engineering.
\end{abstract}

Results: A proline degradation-deficient E. coli strain was constructed by deleting the putA gene encoding proline dehydrogenase. Whole-cell biotransformations with this mutant strain led not only to quantitative proline hydroxylation but also to a doubling of the specific trans-4-L-hydroxyproline (hyp) formation rate, compared to the wild type. Analysis of carbon flux through central metabolism of the mutant strain revealed that the increased $a-K G$ demand for P4H activity did not enhance the $a-K G$ generating flux, indicating a tightly regulated TCA cycle operation under the conditions studied. In the wild type strain, P4H synthesis and catalysis caused a reduction in biomass yield. Interestingly, the $\triangle$ putA strain additionally compensated the associated ATP and NADH loss by reducing maintenance energy demands at comparably low glucose uptake rates, instead of increasing the TCA activity.

Conclusions: The putA knockout in recombinant E. coli BL21(DE3)(pLysS) was found to be promising for productive $\mathrm{P} 4 \mathrm{H}$ catalysis not only in terms of biotransformation yield, but also regarding the rates for biotransformation and proline uptake and the yield of hyp on the energy source. The results indicate that, upon a putA knockout, the coupling of the TCA-cycle to proline hydroxylation via the cosubstrate $a-K G$ becomes a key factor constraining and a target to further improve the efficiency of $a$-KG-dependent biotransformations.

Keywords: Whole-cell biocatalysis, Proline hydroxylation, Strain engineering, Metabolic flux analysis, Biocatalyst efficiency

\footnotetext{
*Correspondence: bruno.buehler@ufz.de

${ }^{1}$ Department of Biochemical and Chemical Engineering, Laboratory

of Chemical Biotechnology, TU Dortmund University, Emil-Figge-Strasse

66, 44227 Dortmund, Germany

Full list of author information is available at the end of the article
} 


\section{Background}

$\mathrm{Fe}(\mathrm{II}) \alpha$-ketoglutarate-dependent dioxygenases are nonheme iron-containing oxygenases coupling dioxygen activation to the oxidative decarboxylation of $\alpha$-ketoglutarate $(\alpha-K G)$. These enzymes catalyze a remarkable range of reactions, such as hydroxylation, desaturation, and epoxidation $[1,2]$. In the hydroxylation reaction catalyzed by proline-4-hydroxylase $(\mathrm{P} 4 \mathrm{H})$, one atom of molecular oxygen is introduced into L-proline to give trans-4-hydroxyL-proline (hyp), a valuable intermediate for the synthesis of chiral pharmaceuticals and antibiotics [3], while the other oxygen atom is introduced into the cosubstrate $\alpha$ $\mathrm{KG}$ to give succinate and $\mathrm{CO}_{2}$ upon oxidative decarboxylation [4].

For an economically viable process that utilizes $\mathrm{P} 4 \mathrm{H}$ or other $\alpha$-KG-dependent dioxygenases, microbial cells are the preferred biocatalysts, since $\alpha$-KG is a central metabolite and can be supplied continuously by host metabolism, namely the tricarboxylic acid (TCA) cycle. Thus, the biocatalytic target reaction creates a short-cut in the
TCA cycle that intertwines whole-cell catalytic efficiency with microbial metabolism and physiology (Fig. 1). When using whole-cell biocatalysts, numerous physiologyrelated factors can potentially interfere with catalytic performance, i.e., limited substrate uptake or cosubstrate supply, substrate or product metabolization by host intrinsic enzymes, by-product formation, and toxicity of substrates and products [5-7]. Therefore, retrofitting of cellular functionalities is often necessary to overcome unwanted constraints and to obtain efficient and robust microbial cell factories specifically tailored to meet commercial biotechnological objectives $[8,9]$.

For the synthesis of hyp from proline, a commercially used whole-cell process has already been reported [10]. However, the interdependency of process conditions, host metabolism, and catalyst performance has not been unraveled yet. Using $\mathrm{P} 4 \mathrm{H}$ containing recombinant Escherichia coli cells, it was recently demonstrated that there is a strong interference of catalytic activity with the regulation of proline uptake and metabolism [11]. In E. coli,

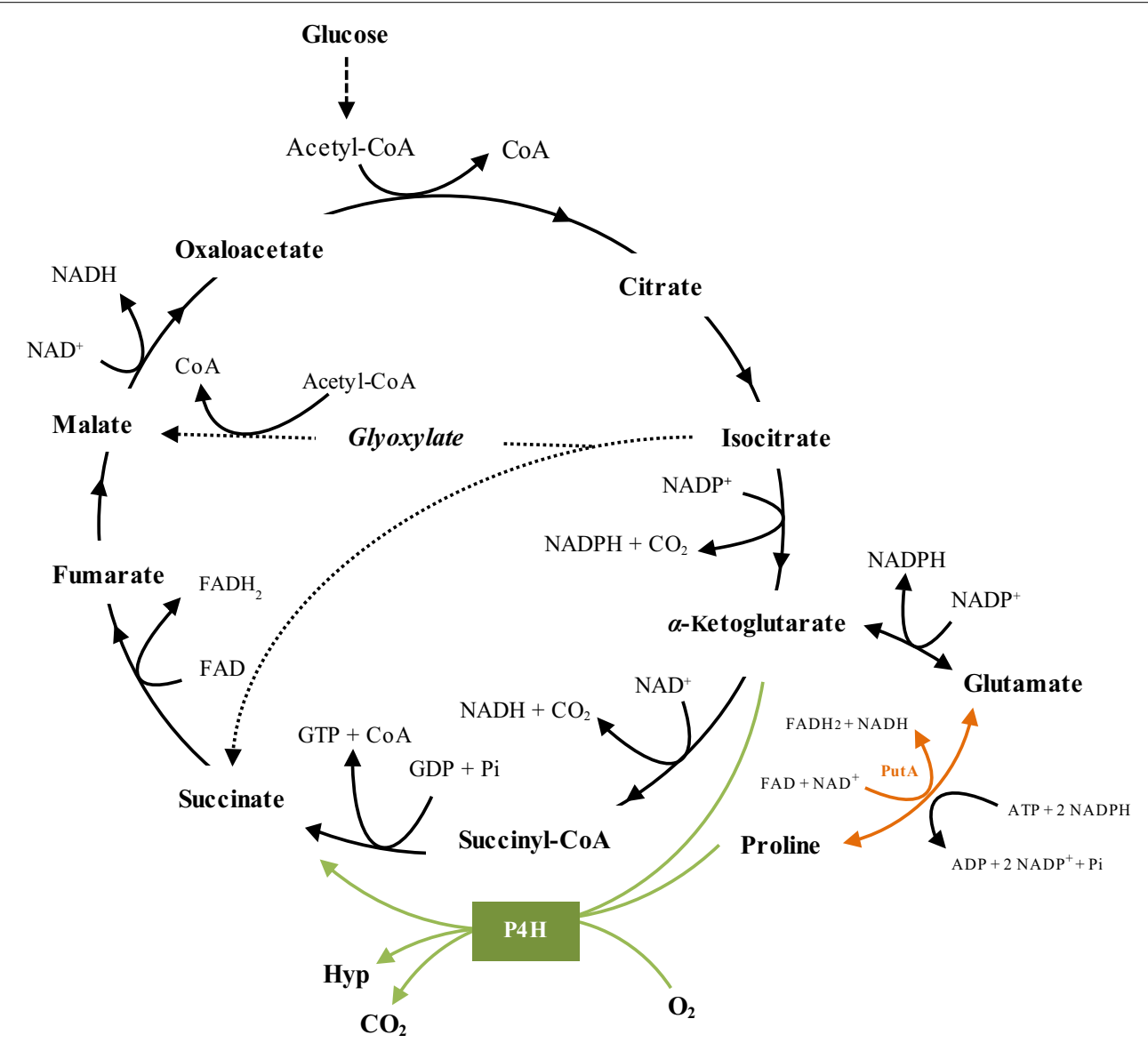

Fig. 1 Schematic representation of the interconnection between trans-4-hydroxy-L-proline (hyp) synthesis catalyzed by recombinant Escherichia coli containing proline-4-hydroxylase (P4H) and central carbon metabolism. 
proline degradation requires two genes, putP and putA, encoding the $\mathrm{Na}^{+}$/proline symport carrier (PutP) and the multifunctional proline utilization protein A (PutA), respectively [12]. Depending on proline availability, PutA functions either as a DNA-binding transcriptional repressor of putA and putP expression (low proline levels) or as a membrane-bound bi-functional dehydrogenase responsible for the two-step oxidation of proline to glutamate (high proline levels). PutA is thus involved in both, proline catabolism and its transcriptional regulation [13]. For biocatalytically active growing cells, a catalysis-induced reduction of proline uptake was observed, which correlated with reduced transcription of $p u t A$ and $p u t P$, demonstrating that proline uptake and competition of hyp formation from proline by $\mathrm{P} 4 \mathrm{H}$ with proline catabolism were the key factors limiting biocatalyst efficiency [11].

In this study, E. coli BL21(DE3)(pLysS), a potent host strain for $\mathrm{P} 4 \mathrm{H}$ catalysis ([11], hereafter referred to as wt), overexpressing a codon-optimized $p 4 h$ gene ( $p 4 h 1 o f)$ was rationally engineered to further comprehend and modulate the interplay between cellular physiology and proline hydroxylation. Toward this goal, a knockout mutant lacking the putA gene (E. coli BL21 $\triangle p u t A(\mathrm{DE} 3)(\mathrm{pLysS})$, referred to as $\triangle p u t A$ ) was constructed and physiologically characterized. This mutation eliminated both proline oxidation to glutamate and transcriptional repression of the put operon. Using ${ }^{13} \mathrm{C}$-based metabolic flux analysis $\left({ }^{13} \mathrm{C}\right.$-MFA), the metabolic response of the whole-cell catalyst upon genetic (i.e., putA deletion, $p 4 h 1$ of expression) and environmental perturbations (i.e., proline addition, product synthesis) was assessed. Furthermore, energy and redox metabolism were investigated via ${ }^{13} \mathrm{C}$ MFA to reveal how the cells attune their bioenergetic status upon product synthesis and under various growth conditions.

\section{Results and discussion}

\section{Proline degradation deficiency increases both hyp yield} and formation rate

To determine how proline metabolism and its regulation affect the physiology of a proline-hydroxylating biocatalyst, the impact of the putA deletion on exponential growth parameters and hyp synthesis was investigated. The engineered strain, bearing either pET-24a ( $\triangle p u t A_{-}$ pET) or pET_p4h1of ( $\left.\triangle p u t A \_p 4 h 1 o f\right)$, was incubated aerobically in M9 minimal medium with glucose as carbon and energy source in the presence or absence of proline and compared with the wildtype strain cultivated under the same conditions (Table 1).

In case of pET-24a containing wildtype cells (wt_pET) grown in the presence of proline, PutA associates with the membrane, catalyzing the first steps of proline degradation to glutamate [12]. Glutamate is subsequently deaminated to the TCA cycle intermediate $\alpha$-KG, supplying additional carbon, nitrogen, and energy to the cells. This ability of the wildtype to catabolize proline together with glucose led to an increase in growth rate, final biomass titer, and biomass yield on glucose, compared to growth on glucose alone. On the contrary, the mutant strain $\triangle p u t A$ was, as expected, unable to degrade proline. The specific growth rate $(\mu)$, final biomass titer, and biomass yield on glucose of the $\triangle p u t A \_$pET strain were virtually unchanged upon

Table 1 Physiological comparison of aerobically growing recombinant E. coli BL21(DE3)(pLysS) strains

\begin{tabular}{|c|c|c|c|c|c|c|c|c|}
\hline & \multicolumn{2}{|l|}{ wt_pET } & \multicolumn{2}{|l|}{$\Delta p u t A \_p E T$} & \multicolumn{2}{|l|}{ wt_p4h1 of } & \multicolumn{2}{|l|}{$\Delta p u t A \_\mathrm{p} 4 \mathrm{~h} 1$ of } \\
\hline & -Pro & +Pro & -Pro & +Pro & -Pro & +Pro & -Pro & +Pro \\
\hline $\boldsymbol{\mu}\left(h^{-1}\right)$ & $0.44 \pm 0.01$ & $0.48 \pm 0.01$ & $0.42 \pm 0.01$ & $0.43 \pm 0.01$ & $0.32 \pm 0.02$ & $0.33 \pm 0.00$ & $0.3 \pm 0.01$ & $0.32 \pm 0.01$ \\
\hline Final biomass ( $\left.g_{\mathrm{CDW}} \mathrm{L}^{-1}\right)$ & $1.9 \pm 0.1$ & $2.2 \pm 0.1$ & $2.0 \pm 0.1$ & $2.0 \pm 0.1$ & $1.4 \pm 0.1$ & $1.8 \pm 0.1$ & $1.5 \pm 0.1$ & $1.5 \pm 0.1$ \\
\hline $\boldsymbol{r}_{\text {Glucose }}\left(\mathrm{mmol} \mathrm{g}^{-1} \mathrm{~h}^{-1}\right)$ & $-5.3 \pm 0.3$ & $-5.1 \pm 0.1$ & $-5.2 \pm 0.2$ & $-5.1 \pm 0.2$ & $-4.8 \pm 0.3$ & $-4.4 \pm 0.3$ & $-4.7 \pm 0.2$ & $-3.9 \pm 0.1$ \\
\hline $\boldsymbol{r}_{\text {Acetate }}\left(\mathrm{mmol} \mathrm{g} \mathrm{h}^{-1}\right)$ & $1.33 \pm 0.1$ & $1.59 \pm 0.2$ & $0.98 \pm 0.1$ & $0.76 \pm 0.1$ & $0.92 \pm 0.1$ & $1.24 \pm 0.1$ & $1.09 \pm 0.04$ & $0.93 \pm 0.1$ \\
\hline $\boldsymbol{r}_{\text {Proline }}\left(\mathrm{mmol} \mathrm{g} \mathrm{h}^{-1}\right)$ & NA & $-1.08 \pm 0.01$ & NA & ND & NA & $-0.68 \pm 0.01$ & NA & $-0.75 \pm 0.01$ \\
\hline $\boldsymbol{r}_{\text {Hyp }}\left(\mathrm{mmol} \mathrm{g} \mathrm{h}{ }^{-1}\right)$ & ND & ND & ND & ND & $0.09 \pm 0.01$ & $0.37 \pm 0.01$ & $0.14 \pm 0.01$ & $0.75 \pm 0.01$ \\
\hline $\boldsymbol{Y}_{\mathrm{x} / \mathrm{g} \mid \mathrm{c}}\left(g_{\mathrm{CDW}} \mathrm{g}_{\mathrm{g} \mid \mathrm{c}}^{-1}\right)$ & $0.46 \pm 0.02$ & $0.52 \pm 0.01$ & $0.45 \pm 0.02$ & $0.47 \pm 0.01$ & $0.39 \pm 0.02$ & $0.42 \pm 0.03$ & $0.36 \pm 0.01$ & $0.45 \pm 0.01$ \\
\hline $\boldsymbol{Y}_{\text {ace/glc }}\left(\mathrm{mol}_{\mathrm{ace}} \mathrm{mol}_{\mathrm{glc}}^{-1}\right)$ & $0.25 \pm 0.03$ & $0.31 \pm 0.04$ & $0.19 \pm 0.03$ & $0.15 \pm 0.01$ & $0.19 \pm 0.01$ & $0.28 \pm 0.01$ & $0.23 \pm 0.01$ & $0.24 \pm 0.03$ \\
\hline $\boldsymbol{Y}_{\text {hyp/pro }}\left(\mathrm{mol}_{\text {hyp }} \mathrm{mol}_{\text {pro }}^{-1}\right)$ & NA & ND & NA & ND & NA & $0.55 \pm 0.01$ & NA & $1 \pm 0.01$ \\
\hline $\boldsymbol{Y}_{\text {hyp } / \mathrm{glc}}\left(\mathrm{mol}_{\text {hyp }} \mathrm{mol}_{\mathrm{glc}}^{-1}\right)$ & ND & ND & ND & ND & $0.019 \pm 0.001$ & $0.084 \pm 0.003$ & $0.030 \pm 0.001$ & $0.192 \pm 0.002$ \\
\hline $\boldsymbol{r}_{\mathrm{Hyp}}\left(\cup \mathrm{g}_{\mathrm{CDW}}{ }^{-1}\right)$ & NA & NA & NA & NA & $1.35 \pm 0.02$ & $6.1 \pm 0.2$ & $2.20 \pm 0.02$ & $12.6 \pm 0.1$ \\
\hline
\end{tabular}

Cultivation was performed at $30^{\circ} \mathrm{C}$ in $\mathrm{M} 9$ medium with $5 \mathrm{~g} \mathrm{~L}^{-1}$ glucose in the absence (-Pro) or presence (+Pro) of $5 \mathrm{mM}$ proline. wt_pET, E. coli BL21(DE3)(pLysS) (pET-24a); $\Delta$ putA_pET, E. coli BL21 $\Delta$ putA(DE3)(pLysS)(pET-24a); wt_p4h1 of, E. coli BL21(DE3)(pLysS)(pET_p4h1 of); $\Delta$ putA_p4h1 of, E.coli BL21 $\Delta$ putA(DE3)(pLysS) (pET_p4h1of); $\mu$, specific growth rate; $r$, specific rates for substrate uptake (negative values) or product formation; CDW, cell dry weight; pro, proline; ace, acetate; hyp, trans-4-hydroxy-L-proline; $Y_{\mathrm{x} / \mathrm{glc}}, Y_{\text {ace/glc }}, Y_{\text {hyp/pro, }}$ and $Y_{\text {hyp/glc }}$ yield coefficients for biomass and acetate on glucose and for hyp on proline and glucose, respectively; ND, not detected; NA, not applicable; $1 \mathrm{U}=1 \mu \mathrm{mol}$ of product formed per min. Values represent the average from three different experiments (biological replicates) with standard deviations displayed as error. 
proline addition and resembled the wt_pET strain grown on glucose (Table 1, see also Additional file 1: Figure S1). Similarly, proline addition had no effect on the growth rate of the $\Delta p u t A_{-}$p4h1of strain. Interestingly, the presence of proline also did not significantly influence the growth rate of the wildtype strain containing pET_p4h1of (wt_ p4h1of). This can be explained by the reduced amount of proline used for biomass formation due to hydroxylation, and the decreased proline uptake rate induced by $\mathrm{P} 4 \mathrm{H}$ activity [11]. Nevertheless, proline addition increased the final biomass titer of the wt_p4h1 of strain.

In all cases, both growth rate and biomass formed were decreased, when $\mathrm{P} 4 \mathrm{H}$ was produced, indicating a metabolic burden imposed by heterologous $\mathrm{P} 4 \mathrm{H}$ synthesis [14]. The glucose uptake rate and the biomass yield on glucose were also reduced upon $\mathrm{P} 4 \mathrm{H}$ synthesis, independently of proline addition, indicating that less energy and metabolite precursors are used for biomass formation. It should be noted that $\mathrm{P} 4 \mathrm{H}$ was successfully produced at constant levels under all conditions studied (see Additional file 1: Figure S2) and that, in the absence of extracellular proline, both wt_p4h1of and $\Delta p u t A \_p 4 h 1$ of could synthesize hyp from endogenous proline. Interestingly, upon proline addition, the $\triangle p u t A_{-} \mathrm{p} 4 \mathrm{~h} 1 \mathrm{of}$ strain displayed the lowest glucose uptake rate $\left(3.9 \mathrm{mmol} \mathrm{g}^{-1} \mathrm{~h}^{-1}\right)$, but its biomass yield on glucose $\left(0.45 \mathrm{~g}_{\mathrm{CDW}} \mathrm{g}_{\text {glc }}^{-1}\right)$ was comparably high, suggesting energy-efficient biomass formation.

Acetate was secreted by all strains under the conditions studied, implying an excess of available acetyl-CoA as a result of the TCA cycle not keeping pace with glycolysis $[15,16]$, and was assimilated after glucose depletion. The specific growth rate was not negatively affected by the relatively low acetate concentrations (from 0.1 to $0.26 \mathrm{~g} \mathrm{~L}^{-1}$, see Additional file 1: Figures S1 and S3), which were below the reported growth-inhibiting acetate concentrations of $0.5-5 \mathrm{~g} \mathrm{~L}^{-1}[17,18]$. While the presence of proline resulted in an increased acetate formation rate in the case of wt_pET and wt_p4h1of, no such effect was observed for the corresponding $\triangle p u t A$ strains. Thus, proline-derived carbon influx into the central metabolism appears to promote overflow metabolism. Interestingly, the $\triangle p u t A \_p E T$ strain showed less acetate formation as the only difference to the wt_pET strain indicating a higher carbon cost of maintenance. However, in the absence of PutA, $\mathrm{P} 4 \mathrm{H}$ synthesis ( $\triangle p u t A \_p 4 h 1$ of) caused an increase in acetate yield on glucose, probably due to the metabolic stress.

Overall, proline hydroxylation profited from the following beneficial effects of putA deletion: (1) quantitative transformation of proline into hyp, (2) doubling of the specific hyp formation rate, and (3) a 2.3-fold higher molar hyp yield on glucose, characterizing this strain as a favorable biocatalyst for proline hydroxylation (Table 1, see also Additional file 1: Figure S3).

\section{Metabolic network operation: $\alpha$-KG formation via the TCA cycle does not increase upon $\mathrm{P} 4 \mathrm{H}$ catalysis}

To investigate how the putA deletion and hyp synthesis affect the operation of the intracellular reaction network, ${ }^{13} \mathrm{C}$-MFA was performed for the wildtype and the $\Delta p u t A$ strain, bearing either pET-24a or pET_p4h1of, during exponential batch growth in the presence and absence of proline in $\mathrm{M} 9$ medium containing labeled glucose $(80 \%$ $\left[1-{ }^{13} \mathrm{C}\right]$ and $20 \%$ [U- $\left.\left.{ }^{13} \mathrm{C}\right]\right)$. The relative carbon flux distributions throughout the central metabolic pathways for all strains and conditions studied, normalized to the glucose uptake rate, are mapped in Fig. 2.

Flux patterns in the upper part of glycolysis (until phosphoenolpyruvate) were similar for all strains and were virtually unaffected by the presence of proline. When using putA-positive strains, unlabeled proline-derived carbon only became evident in amino acids synthesized from TCA cycle intermediates (Table 2). As expected for $\Delta p u t A$ strains, which are unable to channel proline carbon into central metabolism, the unlabeled carbon content in amino acids (except for proline) did not change upon proline addition.

The largest differences among strains were observed in the reactions mediated by the malic enzymes and the phosphoenolpyruvate carboxykinase, the TCA cycle, and the fluxes related to proline metabolism and hydroxylation. As the $\Delta p u t A_{\text {p }}$ ET strain was not able to catabolize proline, proline addition did not have an impact on the flux distribution, which resembled that of the wt_pET strain grown on glucose only. However, the $\Delta p u t A \_p E T$ strain virtually substituted endogenous proline biosynthesis with the uptake of extracellular proline. In contrast, proline addition increased the acetate secretion rate by almost $25 \%$, in the wt_pET strain, reversed the flux between $\alpha$-KG and glutamate towards $\alpha$-KG synthesis, increased the TCA flux from $\alpha$-KG to succinate by almost $40 \%$, and activated the conversion of malate to pyruvate. In all other cases, independently of proline addition, this gluconeogenetic reaction was not active. The oxidative decarboxylation of malate catalyzed by the malic enzymes ScfA and/or MaeB [19] has previously been considered absent in E. coli cells growing on glucose [20]. Such a flux through malic enzymes, for which simulations gave evidence only in the case of the wt_pET strain grown on glucose and proline, was not identified in our earlier study, where the pools of malate and oxaloacetate in the TCA cycle and the pools of pyruvate and phosphoenolpyruvate in glycolysis were lumped [11]. Accordingly, proline addition was suggested to reduce the anaplerotic fluxes. In order to assess whether the malate decarboxylation indeed takes place in vivo, a tracer experiment using $100 \% \mathrm{U}_{-}{ }^{13} \mathrm{C}$ labeled glucose was performed and the fraction of unlabeled alanine derived from proline via 


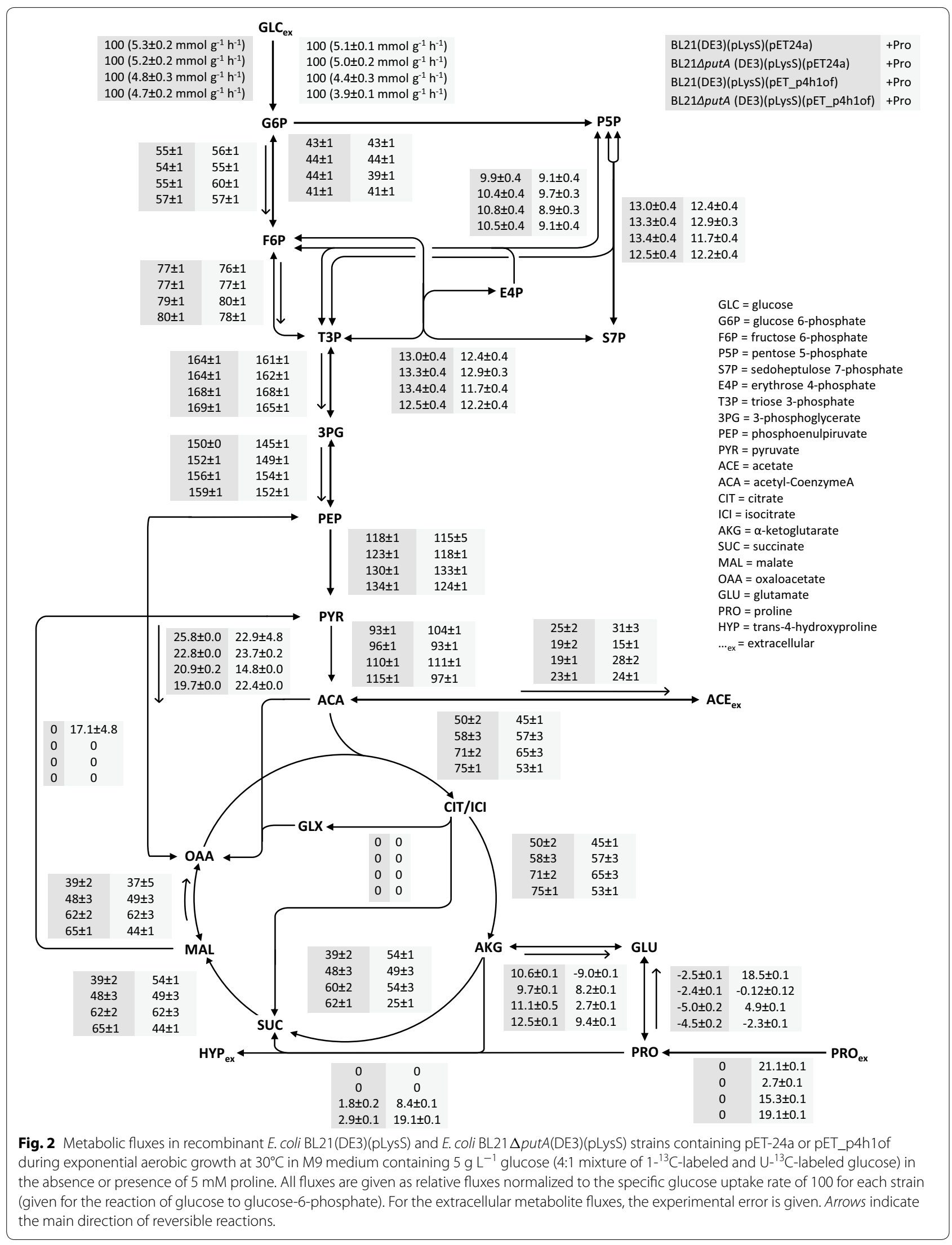


Table 2 Fractional abundance of unlabeled amino acid fragments $(m 0)$ during cultivation on labeled glucose with and without unlabeled proline

\begin{tabular}{|c|c|c|c|c|c|c|c|c|}
\hline & \multicolumn{2}{|c|}{ wt_pET } & \multicolumn{2}{|c|}{$\Delta p u t A \_p E T$} & \multicolumn{2}{|c|}{ wt_p4h1 of } & \multicolumn{2}{|c|}{$\Delta p u t A \_\mathrm{p} 4 \mathrm{~h} 1$ of } \\
\hline & -Pro & +Pro & -Pro & +Pro & -Pro & +Pro & -Pro & + Pro \\
\hline \multicolumn{9}{|l|}{ Glycolysis } \\
\hline Ala $[\mathrm{M}-57]^{+}$ & 0.366 & 0.377 & 0.366 & 0.368 & 0.365 & 0.360 & 0.361 & 0.359 \\
\hline Gly [M-57] $]^{+}$ & 0.622 & 0.624 & 0.621 & 0.622 & 0.621 & 0.621 & 0.619 & 0.620 \\
\hline Val $[M-57]^{+}$ & 0.175 & 0.183 & 0.176 & 0.175 & 0.174 & 0.169 & 0.169 & 0.165 \\
\hline Leu [M-159] ${ }^{+}$ & 0.113 & 0.12 & 0.114 & 0.114 & 0.113 & 0.105 & 0.109 & 0.104 \\
\hline $\operatorname{Ser}[M-57]^{+}$ & 0.319 & 0.322 & 0.321 & 0.321 & 0.313 & 0.311 & 0.313 & 0.310 \\
\hline Phe $[M-57]^{+}$ & 0.111 & 0.114 & 0.111 & 0.110 & 0.113 & 0.109 & 0.109 & 0.108 \\
\hline \multicolumn{9}{|l|}{ TCA } \\
\hline Asp [M-57] ${ }^{+}$ & 0.195 & 0.336 & 0.194 & 0.194 & 0.191 & 0.233 & 0.187 & 0.179 \\
\hline $\operatorname{Thr}[\mathrm{M}-57]^{+}$ & 0.193 & 0.331 & 0.190 & 0.190 & 0.187 & 0.232 & 0.184 & 0.176 \\
\hline Ile [M-159] ${ }^{+}$ & 0.140 & 0.225 & 0.140 & 0.140 & 0.137 & 0.157 & 0.135 & 0.128 \\
\hline Glu [M-57] $]^{+}$ & 0.115 & 0.333 & 0.115 & 0.115 & 0.113 & 0.195 & 0.112 & 0.105 \\
\hline Pro [M-159] ${ }^{+}$ & 0.184 & 0.818 & 0.181 & 0.819 & 0.176 & 0.819 & 0.175 & 0.820 \\
\hline
\end{tabular}

Cells were grown aerobically at $30^{\circ} \mathrm{C}$ in $\mathrm{M} 9$ medium with $5 \mathrm{~g} \mathrm{~L}^{-1}$ labeled glucose $\left(80 \% 1-{ }^{13} \mathrm{C}\right.$ and $\left.20 \% \mathrm{U}-{ }^{13} \mathrm{C}\right)$ in the presence $(+$ Pro) and absence $(-$ Pro) of $5 \mathrm{mM}$ unlabeled proline. wt_pET, E. coli BL21(DE3)(pLysS)(pET-24a); $\Delta$ putA_pET, E. coli BL21 $\Delta$ putA_p4h1 of, E. coli BL21 $\Delta$ putA(DE3)(pLysS)(pET_p4h1 of).

malate and pyruvate was quantified. When proline was added, the unlabeled alanine $m 0$ fraction of the 260,232 , and $158[\mathrm{~m} / \mathrm{z}]$ fragment ions doubled from $1.8,1.8$, and $2.2 \%$ to $3.8,3.4$, and $4.0 \%$, respectively (see Additional file 1: Table S4). This experimentally determined increase, reaching on average approximately $1.8 \%$, is in agreement with the $2.1 \%$ calculated theoretically from the metabolic fluxes presented in Fig. 2, confirming active flux via malic enzymes. The role of malic enzymes is not clear during growth on glucose, since the combined activities of pyruvate carboxylase, malate dehydrogenase, and malic enzymes result in net ATP consumption and can therefore be regarded as parts of a futile cycle. However, it is generally accepted that the flux from malate to pyruvate produces NADPH and thus functions as NADPH generator for biosynthetic purposes when $E$. coli grows on substrates that do not make use of glycolysis to enter central metabolism (e.g., acetate, C4-dicarboxylic acids, amino acids) $[19,21,22]$. Moreover, as phosphoenolpyruvate carboxykinase and the malic enzyme(s) may be responsible for the withdrawal of C4- and C5-intermediates from the TCA cycle, they might fulfil a cataplerotic function [23]. Thus, the addition of proline to the wt_pET strain, accompanied by the increased NADH generating flux from $a-K G$ towards succinate and malate, may have led to malic enzyme activation, pyruvate surplus, and finally a higher acetate excretion rate.

In the absence of proline, $p 4 h 1$ expression and the resulting proline hydroxylation lead to a doubling of the proline synthesis rate in both strains. Additionally, recombinant $\mathrm{P} 4 \mathrm{H}$ production was associated with a metabolic burden as reflected by higher relative TCA fluxes in both wt_p4h1of and $\Delta p u t A \_$p4h1of indicating increased biosynthetic and energy demands. When proline was added to the medium, the same effect was observed for wt_p4h1of, but not for $\Delta p u t A \_p 4 h 1$ of which retained similar relative TCA cycle fluxes as $\triangle p u t A \_p E T$. Another difference between wt_p4h1of and $\Delta p u t A \_p 4 h 1$ of is the anaplerotic net flux between phosphoenolpyruvate and oxaloacetate. Upon proline hydroxylation, this flux decreased by $30 \%$ in wt_p4h1of, implying an anaplerotic role of proline metabolism, whereas it remained similar in $\Delta p u t A \_$p4h1of, as can be expected from the inability of this strain to metabolize proline. However, in wt_pET such an anaplerotic role of proline metabolism was not observed. Instead, the flux through the malic enzymes was activated as described above. For wt_p4h1of, the missing evidence for an activated malic enzyme flux can be explained by a decreased rate of proline metabolism caused by proline hydroxylation and the lower proline uptake rate.

In the presence of proline, the flux from $\alpha-\mathrm{KG}$ to succinate was decreased by $60 \%$ in $\Delta p u t A \_p 4 h 1$ of compared to only $10 \%$ in wt_p4h1of, which can be ascribed to $\alpha$-KG withdrawal for hyp synthesis. Strikingly, even though putA deletion led to increased proline uptake and hydroxylation rates, it did not induce a "driven-bydemand" increase of the $\alpha-K G$ generating TCA flux, pointing towards a possible limitation of $\mathrm{P} 4 \mathrm{H}$ catalysis by the cosubstrate $\alpha$-KG. Moreover, the intracellular $\alpha$-KG 


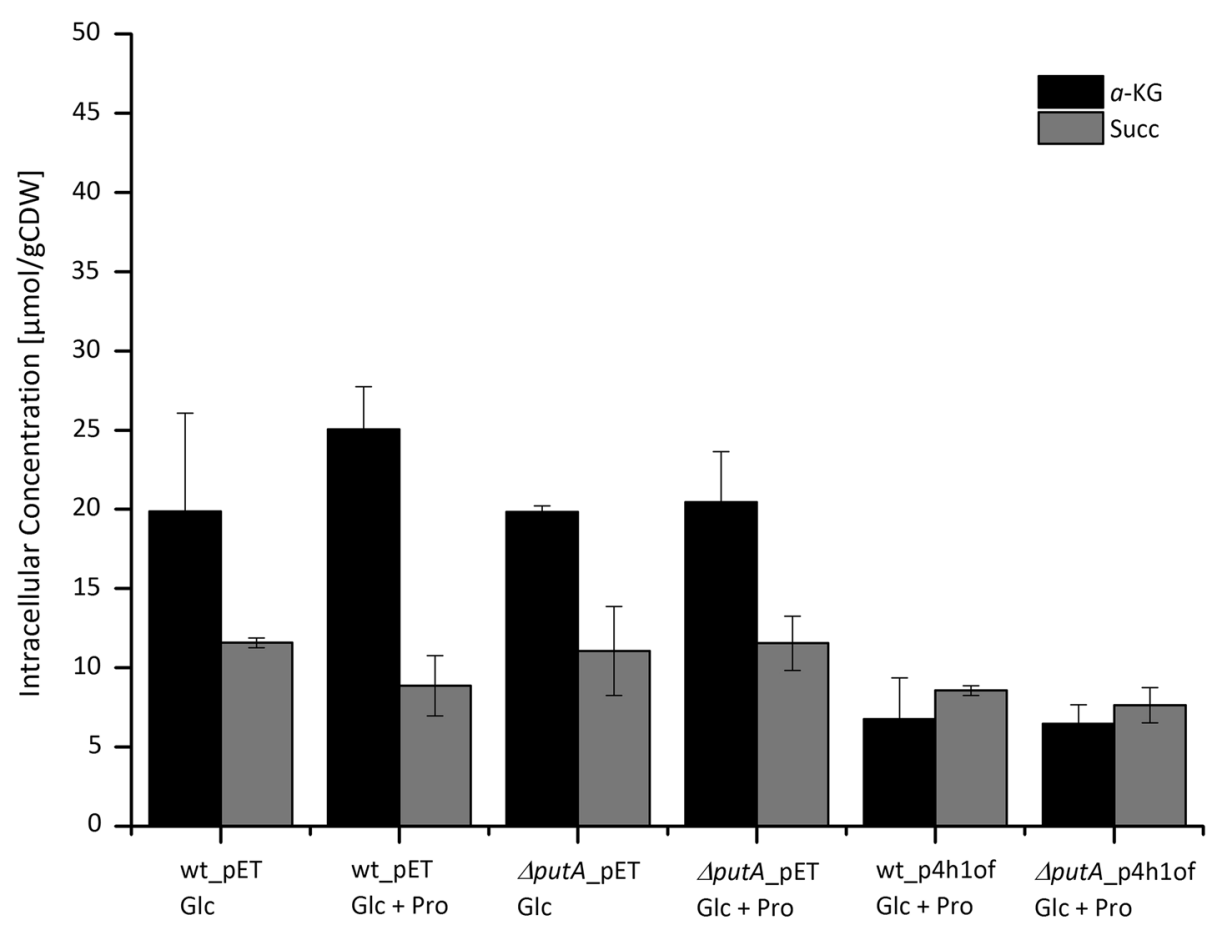

Fig. 3 Intracellular a-ketoglutarate $(a-K G)$ and succinate (Succ) concentrations in the mid-exponential growth phase for recombinant $E$. coli BL21(DE3)(pLysS) (wt) and E. coli BL21 $\Delta$ putA(DE3)(pLysS) ( $\Delta$ putA) containing pET-24a (pET) or pET_p4h1 of (p4h1 of) in M9 medium with $5 \mathrm{~g} \mathrm{~L}{ }^{-1}$ glucose (Glc) in the absence or presence of $5 \mathrm{mM}$ proline (Pro) at $30^{\circ} \mathrm{C}$. Concentrations are given as average values in $\mu$ moles per gram cell dry weight from three different samples with standard deviations displayed as error bars.

concentrations determined for both strains (Fig. 3) show that even though the hyp formation rate is almost twice as high when using the $\Delta p u t A_{-}$p4h1of as compared to wt_p4h1of, $\mathrm{P} 4 \mathrm{H}$ has to withdraw $\alpha-\mathrm{KG}$ from a pool of similar size competing for $\alpha-K G$ with $\alpha$-KG dehydrogenase and glutamate dehydrogenase. These results indicate that the main limitation of proline hydroxylation is shifted from intracellular proline to $\alpha-\mathrm{KG}$ availability and thus to reactions involved in $\alpha-K G$ formation, such as oxidative isocitrate decarboxylation, rendering them promising targets for future metabolic engineering efforts.

\section{Decreased maintenance energy demands upon hyp synthesis}

Even though stoichiometric modelling provides a precious basis to elucidate how cellular metabolism functions and responds to perturbations, it does not directly offer a deeper insight in the way bacterial cells balance catabolic energy generation with anabolic demands, including redox pools. Thus, based on the metabolic fluxes derived from ${ }^{13} \mathrm{C}$-MFA, net formation rates of NTPs (ATP and GTP), NAD(P)H, and $\mathrm{FADH}_{2}$ were determined (Table 3, See also Additional file 1: Table S5). The rate of NTP formation via substrate-level phosphorylation was calculated based on glycolysis, TCA cycle, and acetic acid formation rates. The ATP generating pathway from acetyl-CoA to acetate catalyzed by phosphotransacetylase and acetate kinase was considered, assuming that the flux through pyruvate oxidase B (PoxB) plays a minor role [24]. The growth-related demand for energy and redox equivalents was calculated using a stoichiometric equation for biomass formation generated by the FiatFlux software (see Additional file 2) [25-27]. The equation contains the specific growth rate $(\mu)$ as a variable, thereby considering the differing macromolecular biomass composition at different growth rates [28]. The rate of ATP formation via oxidative phosphorylation was calculated based on the assumptions that (1) the $\mathrm{NADH}$ and $\mathrm{FADH}_{2}$ not used for biomass formation are utilized for ATP formation at the maximum $\mathrm{P} / \mathrm{O}$ ratio $\left(\mathrm{NADH} \rightarrow 3 \mathrm{ATP}, \mathrm{FADH}_{2} \rightarrow 2 \mathrm{ATP}\right)$ [29], and (2) only NADH and not NADPH is oxidized by the respiratory chain [30].

Substrate-level phosphorylation occurred at similar rates with all strains and under all conditions tested except for $\Delta p u t A \_$p4h1of which displayed a significantly lower rate in the presence of proline (Table 3 ). This low NTP formation rate can be explained by the decreased flux from $\alpha$-KG to succinate upon $\mathrm{P} 4 \mathrm{H}$ catalysis at high rates. The NTP consumed by the pET containing strains 
Table 3 Effect of putA deletion, p4h1 of expression, proline addition, and proline hydroxylation on NTP and cofactor formation and consumption rates

\begin{tabular}{|c|c|c|c|c|c|c|c|c|}
\hline & \multicolumn{2}{|c|}{ wt_pET } & \multicolumn{2}{|c|}{$\Delta$ putA_pET } & \multicolumn{2}{|c|}{ wt_p4h1 of } & \multicolumn{2}{|c|}{$\Delta p u t A \_\mathrm{p} 4 \mathrm{~h} 1$ of } \\
\hline & -Pro & +Pro & -Pro & +Pro & -Pro & +Pro & -Pro & +Pro \\
\hline \multicolumn{9}{|c|}{ Catabolismª $^{\mathrm{a}}$} \\
\hline NADPH & 6.4 & 8.0 & 6.8 & 6.8 & 6.6 & 6.2 & 6.4 & 4.7 \\
\hline $\mathrm{NADH}$ & 17.8 & 19.1 & 18.5 & 17.7 & 19.2 & 17.6 & 19.3 & 12.9 \\
\hline $\mathrm{FADH}_{2}$ & 2.1 & 3.7 & 2.5 & 2.5 & 3.0 & 2.9 & 3.1 & 1.7 \\
\hline ATP/GTP & 14.1 & 14.5 & 14.3 & 13.4 & 14.1 & 13.3 & 14.3 & 10.1 \\
\hline \multicolumn{9}{|c|}{ Biomass formation } \\
\hline NADPH & -7.3 & -7.9 & -7.0 & -7.3 & -5.7 & -5.7 & -5.2 & -5.4 \\
\hline $\mathrm{NADH}$ & 1.2 & 1.3 & 1.1 & 1.2 & 0.9 & 0.9 & 0.8 & 0.8 \\
\hline $\mathrm{FADH}_{2}$ & - & - & - & - & - & - & - & - \\
\hline ATP & -7.3 & -8.1 & -7 & -7.3 & -5.4 & -5.4 & -4.9 & -5.1 \\
\hline \multicolumn{9}{|c|}{ Transhydrogenation } \\
\hline NADPH & 0.9 & -0.1 & 0.2 & 0.5 & -0.9 & -0.5 & -1.2 & 0.7 \\
\hline $\mathrm{NADH}$ & -0.9 & 0.1 & -0.2 & -0.5 & 0.9 & 0.5 & 1.2 & -0.7 \\
\hline \multicolumn{9}{|c|}{ Oxidative phosphorylation } \\
\hline NADPH & - & - & - & - & - & - & - & - \\
\hline $\mathrm{NADH}$ & -18.1 & -20.5 & -19.4 & -18.4 & -21.0 & -19.0 & -21.3 & -13.0 \\
\hline $\mathrm{FADH}_{2}$ & -2.1 & -3.7 & -2.5 & -2.5 & -3.0 & -2.9 & -3.1 & -1.7 \\
\hline ATP & 58.4 & 67.3 & 63.3 & 60.1 & 68.9 & 62.3 & 70.0 & 42.5 \\
\hline \multicolumn{9}{|c|}{ Maintenance ${ }^{b}$} \\
\hline ATP & -65.2 & -73.7 & -70.6 & -66.2 & -77.6 & -70.2 & -79.4 & -47.5 \\
\hline
\end{tabular}

E. coli BL21(DE3)(pLysS) strains were grown in M9 medium containing $5 \mathrm{~g} \mathrm{~L}^{-1}$ glucose and optionally $5 \mathrm{mM}$ proline (Pro) at $30^{\circ} \mathrm{C}$ and $250 \mathrm{rpm}$. Rates are given in mmol $\mathrm{g}_{\mathrm{CDW}}^{-1} \mathrm{~h}^{-1}$. wt_pET, E. coli BL21(DE3)(pLysS)(pET-24a); $\Delta$ putA_pET, E. coli BL21 $\Delta$ putA(DE3)(pLysS)(pET-24a); wt_p4h1of, E. coli BL21(DE3)(pLysS)(pET_p4h1of); $\Delta$ putA_ p4h1 of, E. coli BL21 $\triangle$ putA(DE3)(pLysS)(pET_p4h1of)

${ }^{a}$ The calculations were based on the reactions described in Additional file 1: Table S5 and included in the metabolic map presented in Fig. 2.

${ }^{b}$ The ATP costs for maintenance were not divided into growth and non-growth associated maintenance.

for cell growth was at similar levels, except for wt_pET in the presence of proline which showed a higher NTP demand due to increased biomass formation resulting from proline assimilation.

Upon P4H synthesis, the NTP amounts invested for cell growth on glucose decreased by 26 and $30 \%$ for the wt_p4h1of and $\Delta$ putA_p4h1of, respectively. The same phenomenon was observed when proline was added to the medium, i.e., 33 and $30 \%$ decrease of cell growthassociated NTP consumption, respectively. The metabolic burden of $\mathrm{P} 4 \mathrm{H}$ production imposed on the cells when grown on glucose as sole source of carbon was also manifested by an increased respiratory activity that led to 18 and $10 \%$ higher NTP formation rates in wt_p4h1of and $\Delta$ putA_p4h1of, respectively, and this at a lower growth rate [31, 32]. Accordingly, enhanced maintenance requirements were observed during recombinant protein production as a non-growth associated function that is in agreement with other published results [32,33]. This situation changed when proline was added to the medium. In $\Delta p u t A \_$p4h1of, the NADH generating flux from $\alpha$-KG to succinate was partially replaced by the biotransformation and, in wt_p4h1of, less proline was converted to glutamate, both resulting in decreased $\mathrm{NADH} / \mathrm{FADH}_{2}$ formation and thus reduced oxidative phosphorylation. This effect was more prominent for $\Delta p u t A \_p 4 h 1$ of.

ATP produced and not consumed for growth-related production of cellular material typically is consumed for maintenance processes such as maintenance of electrochemical gradients across the plasma membrane that can reach up to $50 \%$ of the ATP produced, degradation and regeneration of cellular macromolecules, futile cycles, energy spilling reactions, proofreading, and cell motility $[34,35]$. Based on the calculations performed for $\triangle p u t A_{-}$ p4h1of, the most noteworthy bioenergetic alteration caused by $\mathrm{P} 4 \mathrm{H}$ activity consists in the dramatic decrease of NADH available for oxidative phosphorylation. Most interestingly, it seems that, upon hyp synthesis, the engineered strain responded by optimizing its energetic efficiency by reducing its maintenance energy demand instead of increasing the TCA activity. This is especially remarkable as recombinant $p 4 h 1$ of expression itself had 
the opposite effect increasing the energy demand. Taking into account that the stoichiometry of energy transducing membranes is not fixed and that the maximum $\mathrm{P} / \mathrm{O}$ ratios assumed in Table 3 will not be reached in reality, the engineered strain may possibly utilize glucose more efficiently by exhibiting a higher in vivo $\mathrm{P} / \mathrm{O}$ ratio.

\section{Conclusions}

In the current study, a putA knockout mutant of E. coli BL21 overproducing $a$-KG-dependent proline-4-hydroxylase $(\mathrm{P} 4 \mathrm{H})$ was generated and physiologically analyzed to uncover the interference of proline hydroxylation with host cell physiology and metabolism. The deletion of the putA gene has already been reported to be a successful engineering strategy for efficient trans-4-hydroxy-L-proline production [10]. Here, a detailed insight into the metabolic operation of engineered E. coli BL21 upon recombinant $\mathrm{P} 4 \mathrm{H}$ catalysis is provided. The results show that the mutant strain unable to catabolize proline displayed not only a higher yield of hyp on proline, but also a higher specific hyp formation rate and a higher hyp yield on glucose as compared to the wildtype. Metabolic flux analysis revealed that, although the hyp formation rate increased when using the mutant strain, the TCA flux supplying $a$-KG (isocitrate to $a$-KG) did not increase upon accelerated $\mathrm{P} 4 \mathrm{H}$ catalysis, leading to improved glucose utilization efficiency and pointing to a possible limitation in $a$-KG. Furthermore, a redox and energy balance study based on the ${ }^{13} \mathrm{C}$-MFA allowed a quantitative assessment of how the cells coordinate catabolism with anabolism during product synthesis. It was shown that $\mathrm{P} 4 \mathrm{H}$ catalyzed proline hydroxylation in the mutant strain decreases TCA-mediated energy formation by $25 \%$ compared to the wildtype. Obviously, the engineered strain compensated this ATP loss by reducing its maintenance energy demand, e.g., by improving the $\mathrm{P} / \mathrm{O}$ ratio for more efficient glucose utilization, emphasizing the role of maintenance and respiratory chain operation in dynamic cellular adaptation strategies.

\section{Methods}

\section{Chemicals}

${ }^{1-}{ }^{13} \mathrm{C}(99 \%)$ and $\mathrm{U}_{-}{ }^{13} \mathrm{C}$ labeled glucose (99\%) was purchased either from Sigma-Aldrich (Munich, Germany) or Cambridge Isotope Laboratories (Andover, MA, USA); L-proline was kindly provided by Evonik Rexim SAS (Ham, France); all other chemicals were purchased from SigmaAldrich (Munich, Germany) or Carl-Roth (Karlsruhe, Germany) and were of the highest purity available.

\section{Bacterial strains, plasmids, and cultivation conditions}

The strains and plasmids used in this study are listed in Additional file 1: Table S6. For the putA gene deletion, the Quick \& Easy E.coli Gene Deletion Kit based on $\operatorname{Red}^{\circledR} / E^{\circledR}{ }^{\circledR}$ Recombination (Gene Bridges GmbH, Heidelberg, Germany) was used. Recombinant $E$. coli strains were routinely precultured in LB complex medium [36] followed by precultivation and cultivation in $\mathrm{M} 9 \mathrm{~min}$ eral medium composed of $8.5 \mathrm{~g} \mathrm{~L}^{-1} \mathrm{Na}_{2} \mathrm{HPO}_{4} \cdot 2 \mathrm{H}_{2} \mathrm{O}$, $3.0 \mathrm{~g} \mathrm{~L}^{-1} \mathrm{KH}_{2} \mathrm{PO}_{4}, 0.5 \mathrm{~g} \mathrm{~L}^{-1} \mathrm{NaCl}, 1.0 \mathrm{~g} \mathrm{~L}^{-1} \mathrm{NH}_{4} \mathrm{Cl}$, and $2 \mathrm{~mL} \mathrm{~L}^{-1} 1 \mathrm{M} \mathrm{MgSO}_{4}$, which contained $10 \mathrm{mg} \mathrm{L}^{-1}$ thiamine, $5 \mathrm{mg} \mathrm{L}^{-1}$ biotin, $1 \mathrm{~mL} \mathrm{~L}^{-1} \mathrm{US}^{\mathrm{Fe}}$ trace element solution [37], $5 \mathrm{~g} \mathrm{~L}^{-1}$ glucose, $5 \mathrm{mM}$ proline (when specified), $34 \mathrm{mg} \mathrm{L}^{-1}$ chloramphenicol, and $50 \mathrm{mg} \mathrm{L}^{-1}$ kanamycin. Such M9 medium was used for main cultures using non-labeled glucose to investigate the physiology and ${ }^{13} \mathrm{C}$-labeled glucose to perform tracer experiments. For the induction of $p 4 h 1$ of expression, $1 \mathrm{mM}$ isopropyl- $\beta$-Dthiogalactopyranoside (IPTG) was added to both the M9 preculture and the main culture at inoculation. All strains were incubated in baffled Erlenmeyer flasks in horizontal shakers at $30^{\circ} \mathrm{C}$ and $250 \mathrm{rpm}$.

\section{Analytical procedures}

Bacterial cell growth was monitored by measuring the optical density at $600 \mathrm{~nm}\left(\mathrm{OD}_{600}\right)$, using a Libra S11 spectrophotometer (Biochrom Ltd., Cambridge, UK). The correlation factors between $\mathrm{OD}_{600}$ and cell dry weight $(\mathrm{CDW})$ concentration under the conditions investigated were determined as described elsewhere [38] and are listed in the Additional file 1: Table S7. For the determination of extracellular consumption and secretion rates, samples taken during exponential growth were centrifuged for $10 \mathrm{~min}$ at $4^{\circ} \mathrm{C}$ and 13,000 g. Glucose and acetate were quantified in the resulting supernatants using a LaChrom Elite ${ }^{\circledR}$ HPLC System (VWR International $\mathrm{GmbH}$, Darmstadt, Germany) equipped with a Trentec 308R-Gel.H ion exclusion column $(300 \times 8 \mathrm{~mm}$, Trentec Analysentechnik, Gerlingen, Germany) at $40^{\circ} \mathrm{C}$ with $5 \mathrm{mM} \mathrm{H}_{2} \mathrm{SO}_{4}$ as mobile phase at a flow rate of $1 \mathrm{~mL} \mathrm{~min}{ }^{-1}$. Analytes were detected either by a UV $(\lambda=210 \mathrm{~nm})$ (VWR Hitachi L-2420) or refractive index (RI) detector (VWR Hitachi L-2490). Proline and hyp were quantified using a LaChrom Elite ${ }^{\circledR}$ HPLC System (VWR International GmbH, Darmstadt, Germany) equipped with a diode array detector (VWR Hitachi L-2450) at $200 \mathrm{~nm}$ and an Intersil ODS-3 column (GL Sciences B.V., Eindhoven, Netherlands). The separation was performed at $22^{\circ} \mathrm{C}$ and $1 \mathrm{~mL} \mathrm{~min}^{-1}$ flow rate applying a linear gradient profile based on $20 \mathrm{mM} \mathrm{KH_{2 }} \mathrm{PO}_{4}$ buffer ( $\mathrm{pH}$ 2.3) containing $1 \%(\mathrm{v} / \mathrm{v})$ acetonitrile as eluent $\mathrm{A}$ and acetonitrile containing $10 \%(\mathrm{v} / \mathrm{v})$ water as eluent $\mathrm{B}$ as follows: $85 \%$ eluent $A$ for $2 \mathrm{~min}, 85 \%$ to $70 \%$ eluent $A$ within $4 \mathrm{~min}, 70 \%$ eluent $\mathrm{A}$ for $8 \mathrm{~min}$, and $70-85 \%$ eluent A within $0.5 \mathrm{~min}$. Before analysis, the analytes were derivatized using benzoyl chloride. Briefly, supernatant was 
vortex-mixed with $100 \mathrm{mM}$ benzoyl chloride in acetonitrile and $0.5 \mathrm{M} \mathrm{K}_{2} \mathrm{HPO}_{4}(\mathrm{pH} 11.7)$ in a 1:2.5:9 (v/v) ratio followed by incubation for $10 \mathrm{~min}$ at room temperature and $20 \mathrm{~min}$ at $50^{\circ} \mathrm{C}$ with stirring. Before analysis, derivatized samples were diluted in a 4:1 ratio using eluent A and 50\% phosphoric acid in a 7.5:1 (v/v) ratio. Alternatively, a spectrophotometric method described elsewhere [11] was used for hyp quantification. SDS-PAGE was performed to monitor recombinant protein production [39] using an AlphaImager HP documentation system (Biozym, Hessisch Oldendorf, Germany) for gel imaging.

The quantification of intracellular metabolites was based on a modified fast filtration method described by Bolten et al. [40]. Briefly, cells were separated from the medium via vacuum filtration using a water jet pump and cellulose nitrate filter membranes (Whatman, pore size: $0.2 \mu \mathrm{m})$. Two milliliters of cell culture were transferred onto the filter membrane and washed twice with $5 \mathrm{~mL}$ of washing solution $(\mathrm{NaCl}$ solution with an osmolarity equivalent to the M9 medium). The filter was put upside-down into a $100 \mathrm{~mL}$ Schott flask that contained $2 \mathrm{~mL}$ of ice-cold extraction solution (45:45:1:9 of acetonitrile, 2,2,2-trifluoroethanol, trifluoroacetic acid, and water [41]) and incubated for $20 \mathrm{~min}$. The quenching was performed in less than $1 \mathrm{~min}$. The extraction solution was then transferred to $2 \mathrm{~mL}$ Eppendorf tubes and centrifuged for $5 \mathrm{~min}$ at $4^{\circ} \mathrm{C}$ and $13,300 \mathrm{rpm}$. The supernatant was then derivatized for GC-MS analysis in two-steps, first oximation using an aqueous methoxylamine solution and then silylation using MBDSTF [42].

\section{${ }^{13} \mathrm{C}$-labeling experiments}

E. coli strains (wildtype and $\Delta p u t A$ ) were precultured aerobically in $5 \mathrm{~mL}$ M9 minimal medium supplemented with $5 \mathrm{~g} \mathrm{~L}^{-1}$ of glucose at $30^{\circ} \mathrm{C}$ and $250 \mathrm{rpm}$. In the midexponential growth phase, cells were harvested by centrifugation at $4,000 \mathrm{~g}$ and $4^{\circ} \mathrm{C}$ for $5 \mathrm{~min}$, washed once with M9 medium to remove unlabeled glucose, and used to inoculate $\mathrm{M} 9$ medium containing $5 \mathrm{~g} \mathrm{~L}^{-1}$ of a $4: 1 \mathrm{mix}-$ ture of $1-{ }^{13} \mathrm{C}$-labeled and $\mathrm{U}_{-}{ }^{13} \mathrm{C}$ labeled glucose to an $\mathrm{OD}_{600}$ of 0.05 or lower to minimize introduction of nonlabeled carbon from precultivation. For labeling analysis of proteinogenic amino acids, cells were harvested in the mid-exponential growth phase (at an $\mathrm{OD}_{600}$ of 2-2.5) by centrifugation for $10 \mathrm{~min}$ at $13,000 \mathrm{~g}$ and $4^{\circ} \mathrm{C}$, and washed twice by resuspension in $1 \mathrm{~mL} 0.9 \%(\mathrm{w} / \mathrm{v}) \mathrm{NaCl}$. The washed pellet was resuspended in $150 \mu \mathrm{L}$ of $6 \mathrm{M} \mathrm{HCl}$ and hydrolyzed for $6 \mathrm{~h}$ at $105^{\circ} \mathrm{C}$ in a well-sealed vial to prevent evaporation. After drying overnight at $85^{\circ} \mathrm{C}$, the hydrolyzate was resuspended in $30 \mu \mathrm{L}$ acetonitrile, and amino acid silylation was initiated by the addition of $30 \mu \mathrm{l} \quad \mathrm{N}$-methyl- $\mathrm{N}$-tert-butyldimethylsilyl-trifluoracetamide (MBDSTFA) followed by incubation at $85^{\circ} \mathrm{C}$ for
$60 \mathrm{~min}$. The quantification of mass isotopomer distributions (MIDs) of 12 amino acids (alanine, glycine, valine, leucine, isoleucine, proline, serine, threonine, phenylalanine, aspartate, glutamate, tyrosine) from biomass hydrolyzates was performed as previously described [43] using a GC 3800 combined with a MS/MS 1,200 unit (Varian Deutschland GmbH, Darmstadt, Germany).

\section{Metabolic modeling and calculation of metabolic fluxes}

The metabolic network of $E$. coli was adapted from literature [20,44] and comprised glycolysis (EMP), pentose phosphate pathway (PPP), tricarboxylic acid (TCA) cycle with the glyoxylate bypass, anaplerotic carboxylation and decarboxylation reactions, acetate formation, proline hydroxylation, and the reactions among proline, glutamate, and $\alpha$-ketoglutarate $(\alpha-K G)$. The stoichiometric model contained 58 reactions and 38 metabolites in case of growth on glucose only, and 65 reactions and 40 metabolites in case proline was added to the medium. The model was constrained with (1) 4 extracellular fluxes (glucose and proline uptake and acetate and hyp formation), (2) the anabolic precursor requirements for biomass formation, as previously described [44], corrected for the experimentally determined biomass yield on glucose, and (3) the ${ }^{13} \mathrm{C}$-isotopomer labeling pattern of proteinogenic amino acids. Given that the glyoxylate bypass is considered to be inactive in $E$. coli grown on glucose and active when grown on acetate [24], the pathway was set to zero. Quantitative analysis of the intracellular metabolic fluxes was performed with OpenFlux [45] and all numerical calculations with Matlab 7.9 (The Mathworks Inc., Natick, MA, USA). The best-fit values of the intracellular carbon fluxes were estimated by minimizing the deviation between experimentally determined and simulated MIDs. Standard deviations were estimated using the Monte Carlo approach included in OpenFLUX and expressed as upper and lower boundaries for intervals of $95 \%$ confidence [46]. Stoichiometries and related files are presented in the Additional file 3.

Rates for in vivo energy production in the form of NTP and redox cofactors $\mathrm{NAD}(\mathrm{P}) \mathrm{H}$ and $\mathrm{FADH}_{2}$ were estimated from the catabolic reactions using the optimal set of fluxes obtained from ${ }^{13} \mathrm{C}$-MFA. Growthrelated NADPH and ATP consumption rates were estimated using a lumped stoichiometric equation for biomass formation derived from the FiatFlux software [26], in which the growth rate is integrated considering that macromolecular biomass composition is growth rate dependent [47] (see Additional file 2). Maximal ATP formation rates via electron transport chain and oxidative phosphorylation were estimated using the maximum theoretical $\mathrm{P} / \mathrm{O}$ ratios of 3 and 2 for $\mathrm{NADH}$ 
and $\mathrm{FADH}_{2}$, respectively [29]. Maximal NAD(P)H and ATP demands for maintenance were calculated by subtracting the growth-related consumption rate from the production rate.

\section{Additional files}

Additional file 1: Figure S1. Physiology of recombinant E. coli BL21(DE3)(pLysS) strains bearing pET-24a. Panel A and B show biomass formation (circles), glucose consumption (squares), acetate formation (triangles), and proline consumption (diamonds) during batch cultivation of wildtype (closed symbols) and $\Delta$ putA (open symbols) strains at $30^{\circ} \mathrm{C}$ in $\mathrm{M} 9$ medium supplemented with $5 \mathrm{~g} \mathrm{~L}^{-1}$ glucose in the absence (A) or presence (B) of $5 \mathrm{mM}$ proline, respectively. Figure S2. SDS-PAGE analysis of recombinant E. coli BL21(DE3)(pLysS) (pET_p4h1 of) and E. coli BL21 $\triangle p$ utA (DE3) (pLysS) (pET_p4h1 of) at different time points during growth in $\mathrm{M} 9$ medium with $5 \mathrm{~g} \mathrm{~L}^{-1}$ glucose (glc) only or with addition of $5 \mathrm{mM}$ proline (pro) at $30^{\circ} \mathrm{C}$. M: protein size marker. Figure $\mathbf{S 3}$. Physiology of recombinant E. coli BL21(DE3)(pLysS) strains bearing pET_p4h1 of. Biomass formation (circles), glucose consumption (squares), acetate formation (triangles), hyp formation (stars), and proline consumption (diamonds) during batch cultivation of wildtype (closed symbols) and $\Delta p u t A$ (open symbols) strains are shown. Cultivation was performed at $30^{\circ} \mathrm{C}$ in $\mathrm{M} 9$ medium supplemented with $5 \mathrm{~g} \mathrm{~L}^{-1}$ glucose in the absence (panel A) or presence of $5 \mathrm{mM}$ proline (panels B and C). Table S4. Mass isotopomer distribution of alanine for the wt_pET strain at $30^{\circ} \mathrm{C}$ in $\mathrm{M} 9$ medium supplemented with $5 \mathrm{~g} \mathrm{~L}^{-1} \mathrm{U}-{ }^{13} \mathrm{C}$ labeled glucose in the absence or presence of $5 \mathrm{mM}$ proline. Table S5. Reactions of the central carbon metabolism generating or consuming NTP and/or redox equivalents. Table S6. Bacterial strains and plasmids used in this study. Table S7. Correlation factors between OD600 1 and cell dry weight concentration $\left(\mathrm{g}_{\mathrm{CDW}} \mathrm{L}^{-1}\right)$ of the strains used in this study.

Additional file 2. Anabolic demands for biomass formation as a function of the growth rate.

Additional file 3. Supplementary data for ${ }^{13} \mathrm{C}-\mathrm{MFA}$ including reactions considered in the model, comparisons between experimental and simulated mass distribution vectors (MDVs), Monte Carlo analysis, and mass isotopomer distributions of the amino acids.

\section{Abbreviations}

$\alpha$-KG: $\alpha$-ketoglutarate; ATP: adenosine triphosphate; CDW: cell dry weight $\left(\mathrm{g} \mathrm{L}^{-1}\right) ;{ }^{13} \mathrm{C}-\mathrm{MFA}:{ }^{13} \mathrm{C}-$ metabolic flux analysis; Cp: chloramphenicol; EMP: Embden-Meyerhof-Parnas; FAD: flavin adenine dinucleotide; HPLC: high performance liquid chromatography; Glc: glucose; hyp: trans-4-L-hydroxy-proline; IPTG: isopropyl $\beta$-D-thiogalactoside; Km: kanamycin; $\lambda$ : wavelength $(\mathrm{nm})$; LB: lysogeny broth; NAD(P): nicotinamide adenine dinucleotide (phosphate); MBDSTFA: $N$-methyl- $N$-tert-butyldimethylsilyl-trifluoracetamide; MID: mass isotopomer distribution; $\mathrm{OD}_{600}$ : optical density at $600 \mathrm{~nm}$; P/O: phosphate/ oxygen; PPP: pentose phosphate pathway; pro: proline; P4H: proline-4-hydroxylase; putA: proline utilization protein A; putP: $\mathrm{Na}^{+} /$proline symport carrier; RID: refractive index detector; SDS-PAGE: sodium dodecyl sulfate polyacrylamide gel electrophoresis; TCA: tricaboxylic acid; UVNVIS: ultraviolet/visible; wt: wild type; $\mu$ : exponential growth rate $\left(h^{-1}\right) ; \Delta$ putA: knockout of putA gene encoding proline dehydrogenase (PutA).

\section{Authors' contributions}

ET designed, performed the experiments, and drafted the manuscript. BB, OF, and AS participated in the design of the study, supervised it, and participated in writing the manuscript. All authors read and approved the final manuscript.

\section{Author details}

${ }^{1}$ Department of Biochemical and Chemical Engineering, Laboratory of Chemical Biotechnology, TU Dortmund University, Emil-Figge-Strasse 66, 44227 Dortmund, Germany. ${ }^{2}$ Department of Solar Materials, Helmholtz-Centre for Environmental Research - UFZ, Leipzig, Germany.

\section{Acknowledgements}

This work was financially supported by the EU-FP7 Oxygreen project (FP7 EU grant number 212281) and the Mercator Research Center Ruhr (MERCUR, Pr-2013-0010). We thank E. Hart for her experimental assistance regarding intracellular metabolite quantification, F. Falcioni and J. Fu for scientific discussions, and B. Ebert for critical reading of the manuscript.

\section{Compliance with ethical guidelines}

\section{Competing interests}

The authors declare that they have no competing interests.

Received: 23 April 2015 Accepted: 15 July 2015

Published online: 29 July 2015

\section{References}

1. Hausinger RP (2004) Fe(II)/alpha-ketoglutarate-dependent hydroxylases and related enzymes. Crit Rev Biochem Mol Biol 39:21

2. Purpero V, Moran GR (2007) The diverse and pervasive chemistries of the alpha-keto acid dependent enzymes. J Biol Inorg Chem 12:587

3. Remuzon P (1996) Trans-4-hydroxy-L-proline, a useful and versatile chiral starting block. Tetrahedron 52:13803

4. De Carolis E, De Luca V (1994) 2-Oxoglutarate-dependent dioxygenase and related enzymes: biochemical characterization. Phytochemistry 36(5):1093

5. van Beilen JB, Duetz WA, Schmid A, Witholt B (2003) Practical issues in the application of oxygenases. Trends Biotechnol 21:170

6. Cornelissen S, Liu S, Deshmukh AT, Schmid A, Bühler B (2011) Cell physiology rather than enzyme kinetics can determine the efficiency of cytochrome P450-catalyzed C-H-oxyfunctionalization. J Ind Microbiol Biotechnol 38:1359

7. Schrewe M, Julsing MK, Bühler B, Schmid A (2013) Whole-cell biocatalysis for selective and productive $\mathrm{C}-\mathrm{O}$ functional group introduction and modification. Chem Soc Rev 42(15):6346

8. Bailey JE (1991) Toward a science of metabolic engineering. Science 252:1668

9. Woolston BM, Edgar S, Stephanopoulos G (2013) Metabolic engineering past and future. Annu Rev Chem Biomol Eng 4:259

10. Shibasaki T, Mori H, Ozaki A (2000) Enzymatic production of trans-4-hydroxy-L-proline by regio- and stereospecific hydroxylation of L-proline. Biosci Biotechnol Biochem 64:746

11. Falcioni F, Blank LM, Frick O, Karau A, Bühler B, Schmid A (2013) Proline availability regulates proline-4-hydroxylase synthesis and substrate uptake in proline-hydroxylating recombinant Escherichia coli. Appl Environ Microbiol 79(9):3091

12. Lee YH, Nadaraia S, Gu D, Becker DF, Tanner JJ (2003) Structure of the proline dehydrogenase domain of the multifunctional PutA flavoprotein. Nat Struct Biol 10(2):109

13. Zhou Y, Zhu W, Bellur PS, Rewinkel D, Becker DF (2008) Direct linking of metabolism and gene expression in the proline utilization A protein from Escherichia coli. Amino Acids 35(4):711

14. Carneiro S, Ferreira EC, Rocha I (2013) Metabolic responses to recombinant bioprocesses in Escherichia coli. J Biotech 164:396

15. Shiloach J, Kaufman J, Guillard AS, Fass R (1996) Effect of glucose supply strategy on acetate accumulation, growth, and recombinant protein

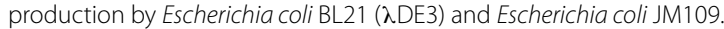
Biotechnol Bioeng 49:421

16. Akesson M, Hagander P, Axelsson JP (2001) Avoiding acetate accumulation in Escherichia coli cultures using feedback control of glucose feeding. Biotechnol Bioeng 73:223

17. Aristidou AA, San KY, Bennett GN (1994) Modification of central metabolic pathway in Escherichia coli to reduce acetate expression of the Bacillus subtilis acetolactate synthase gene. Biotechnol Bioeng 44:944

18. Nakano K, Rischke M, Sato S, Märkl H (1997) Influence of acetic acid on the growth of Escherichia coli K12 during high-cell-density cultivation in a dialysis reactor. Appl Microbiol Biotechnol 48:597 
19. Wang B, Wang P, Zheng E, Chen X, Zhao H, Song P et al (2011) Biochemical properties and physiological roles of NADP-dependent malic enzyme in Escherichia coli. J Microbiol 49(5):797

20. Sauer U, Lasko RW, Fiaux J, Hochuli M, Glaser R, Szyperski T et al (1999) Metabolic flux ratio analysis of genetic and environmental modulations of Escherichia coli central carbon metabolism. J Bacteriol 181:6679

21. Bologna FP, Andreo CS, Drincovich MF (2007) Escherichia coli malic enzymes: two isoforms with substantial differences in kinetic properties, metabolic regulation, and structure. J Bacteriol 189(16):5937

22. Zhao J, Baba T, Mori H, Shimizu K (2004) Global metabolic response of Escherichia coli to gnd or zwf gene-knockout, based on ${ }^{13} \mathrm{C}$-labeling experiments and the measurement of enzyme activities. Appl Microbiol Biotechnol 64:91

23. Sauer U, Eikmanns BJ (2005) The PEP-pyruvate-oxaloacetate node as the switch point for carbon flux distribution in bacteria. FEMS Microbiol Rev 29:765

24. Wolfe AJ (2005) The acetate switch. Microbiol Mol Biol Rev 69(1):12

25. Fischer E, Sauer U (2003) Metabolic flux profiling of Escherichia coli mutants in central carbon metabolism using GC-MS. Eur J Biochem 270(5):880

26. Zamboni N, Fischer E, Sauer U (2005) FiatFlux — a software for metabolic flux analysis from ${ }^{13} \mathrm{C}$-glucose experiments. BMC Bioinform 6:209

27. Nanchen A, Schicker A, Sauer U (2006) Nonlinear dependency of intracellular fluxes on growth rate in miniaturized continuous cultures of Escherichia coli. Appl Environ Microbiol 72(2):1164

28. Bremer H, Dennis PP (1996) Modulation of chemical composition and other parameters of the cell by growth rate. In: Neidhardt FC (ed) Escherichia coli and Salmonella. ASM Press, Washington DC, pp 1553-1569

29. He L, Xiao Y, Gebreselassie N, Zhang F, Antoniewiez MR, Tang YJ et al (2014) Central metabolic responses to the overproduction of fatty acids in Escherichia coli based on ${ }^{13} \mathrm{C}$-metabolic flux analysis. Biotechnol Bioeng 111(3):575

30. Kayser A, Weber J, Hecht V, Rina U (2005) Metabolic flux analysis of Escherichia coli in glucose-limited continuous culture. I. Growth-ratedependent metabolic efficiency at steady state. Microbiology 151:693

31. Hoffmann F, Rinas U (2001) On-line estimation of the metabolic burden resulting from the synthesis of plasmid-encoded and heat-shock proteins by monitoring respiratory energy generation. Biotechnol Bioeng 76:333

32. Weber J, Hoffmann F, Rinas U (2002) Metabolic adaptation of Escherichia coli during temperature-induced recombinant protein production: 2. Redirection of metabolic fluxes. Biotechnol Bioeng 80:320

33. Bhattacharya SK, Dubey AK (1995) Metabolic burden as reflected by maintenance coefficient of recombinant Escherichia coli overexpressing target gene. Biotechnol Lett 17(11):1155

34. Stephanopoulos G, Aristidou AA, Nielsen JH (1998) Metabolic engineering: principles and methodologies. Academic, San Diego

35. Van Bodegom P (2007) Microbial maintenance: a critical review on its quantification. Microb Ecol 53:513
36. Sambrook J, Russell D (2001) Molecular Cloning: a Laboratory Manual, 3rd edn. Cold Spring Harbor Laboratory, Cold Spring Harbor

37. Bühler B, Bollhalder I, Hauer B, Witholt B, Schmid A (2003) Use of the two-liquid phase concept to exploit kinetically controlled multistep biocatalysis. Biotechnol Bioeng 81:683

38. Blank LM, Ebert BE, Bühler B, Schmid A (2008) Metabolic capacity estimation of Escherichia coli as a platform for redox biocatalysis: constraintbased modeling and experimental verification. Biotechnol Bioeng 100:1050

39. Laemmli UK (1970) Cleavage of structural proteins during assembly of head of bacteriophage T4. Nature 227:680-685

40. Bolten CJ, Kiefer P, Letisse F, Portais JC, Wittmann C (2007) Sampling for metabolome analysis of microorganisms. Anal Chem 79:3843

41. Fischer CR, Tseng HC, Tai M, Prather KLJ, Stephanopoulos G (2010) Assessment of heterologous butyrate and butanol pathway activity by measurement of intracellular pathway intermediates in recombinant Escherichia coli. Appl Microbiol Biotechnol 88:265

42. Koek MM, Muilwijk B, van der Werf MJ, Hankemeier T (2006) Microbial metabolomics with gas chromatography/mass spectrometry. Anal Chem 78(4):1272

43. Heyland J, Blank LM, Schmid A (2011) Quantification of metabolic limitations during recombinant protein production in Escherichia coli. J Biotechnol 155:178

44. Fischer E, Zamboni N, Sauer U (2004) High-throughput metabolic flux analysis based on gas chromatography-mass spectrometry derived ${ }^{13} \mathrm{C}$ constraints. Anal Biochem 325(2):308

45. Quek LE, Wittmann C, Nielsen LK, Kromer JO (2009) OpenFLUX: efficient modelling software for ${ }^{13} \mathrm{C}$-based metabolic flux analysis. Microb Cell Fact 8:25

46. Antoniewicz MR, Kelleher JK, Stephanopoulos G (2006) Determination of confidence intervals of metabolic fluxes estimated from stable isotope measurements. Metab Eng 8:324

47. Pramanik J, Keasling JD (1997) Stoichiometric model of Escherichia coli metabolism: incorporation of growth-rate dependent biomass composition and mechanistic energy requirements. Biotechnol Bioeng 56:398

\section{Submit your next manuscript to BioMed Central and take full advantage of:}

- Convenient online submission

- Thorough peer review

- No space constraints or color figure charges

- Immediate publication on acceptance

- Inclusion in PubMed, CAS, Scopus and Google Scholar

- Research which is freely available for redistribution

Submit your manuscript at

www.biomedcentral.com/submit

C BioMed Central 